\title{
Is There an Optimal Age Threshold for Searching for Intestinal Metaplasia on Gastric Mucosa in Western Populations?
}

\author{
Angelo Zullo ${ }^{a}$ Edith Lahner $^{b}$ Cesare Hassan $^{a}$ Bruno Annibale ${ }^{b}$ \\ Gianluca Esposito ${ }^{b}$ \\ ${ }^{a}$ Gastroenterology and Digestive Endoscopy, Nuovo Regina Margherita Hospital, Rome, Italy; ${ }^{\text {b Department of }}$ \\ Medical-Surgical Sciences and Translational Medicine, Sant'Andrea Hospital, Sapienza University of Rome, \\ Rome, Italy
}

\section{Keywords}

Intestinal metaplasia · Gastric cancer · Screening ·

Endoscopy $\cdot$ Age

\section{Abstract}

Introduction: Since screening programs for gastric cancer are not applicable in Western countries, identification and follow-up of gastric precancerous lesions, such as extensive intestinal metaplasia (IM), are worthwhile to increase the diagnosis of cancer at an early stage. We investigated whether an optimal age threshold to detect extensive IM in a European country exists. Methods: This was a post hoc analysis of prospectively collected data in a nationwide study involving consecutive patients aged between 50 and 65 years who underwent an upper endoscopy with the standard 5 gastric biopsies. The presence of extensive (antral and gastric body) IM on gastric mucosa was considered. Results: Data found that the prevalence of extensive IM was distinctly higher in patients aged 60-65 years, with a 2.28-fold increased probability compared to younger patients. None of the other considered factors (sex, BMI, smoking habit, first-degree family history, and symptoms) emerged as an independent predictor of extensive IM in the stomach. Conclusion: When decid- ing for an occasional gastric cancer screening in Western populations, the choice of an age range of 60-65 years might be appropriate, allowing detection of a distinctly high prevalence of extensive IM deserving scheduled follow-up.

(c) 2021 Sociedade Portuguesa de Gastrenterologia Published by S. Karger AG, Basel

\section{Existirá um limite de idade ideal para identificação de metaplasia intestinal na mucosa gástrica em populações Ocidentais?}

\author{
Palavras-chave \\ Metaplasia intestinal - Cancro gástrico · Rastreio · \\ Endoscopia $\cdot$ Idade
}

\section{Resumo \\ Introdução: Como os programas de rastreio de cancro gástrico não se aplicam em populações Ocidentais, a identificação e vigilância de lesões gástricas pré-mali- gnas, como a metaplasia intestinal (MI) extensa, são valio- sas ao aumentar o diagnóstico de cancro em estadios pre-}

(C) 2021 Sociedade Portuguesa de Gastrenterologia. Published by S. Karger AG, Basel

This is an Open Access article licensed under the Creative Commons Attribution-NonCommercial-4.0 International License (CC BY-NC) (http://www.karger.com/Services/OpenAccessLicense), applicable to the online version of the article only. Usage and distribution for commercial purposes requires written permission.
Correspondence to:

Angelo Zullo, angelozullo66@yahoo.it 
coces. Neste estudo, investigamos se existe um limite de idade ideal para detetar metaplasia intestinal num país Europeu. Métodos: Fizemos uma análise post-hoc de dados reunidos prospectivamente de um estudo de base nacional que incluiu doentes consecutivos com idade entre 50 e 65 anos que fizeram endoscopia digestiva alta com colheita protocolada de 5 biopsias gástricas. A presença de Ml extensa (antro e corpo) foi avaliada. Resultados: A prevalência de $\mathrm{Ml}$ extensa foi significativamente superior nos doentes com 60-65 anos, com uma probabilidade 2.28 vezes aumentada quando comparado com doentes mais jovens. Nenhum dos outros potenciais fatores (sexo, indice massa corporal, hábitos tabágicos, história familiar $1^{\circ}$ grau de cancro gástrico e sintomas) se revelou como um fator predictor independente de MI extensa gástrica. Conclusão: Na decisão de rastreio ocasional de cancro gástrico em populações Ocidentais a escolha do intervalo de idade de 60-65 anos pode ser apropriada, permitindo a deteção de uma prevalência significativamente alta de Ml extensa, justificando vigilância programada.

(C) 2021 Sociedade Portuguesa de Gastrenterologia Published by S. Karger AG, Basel

\section{Introduction}

Although its incidence is declining worldwide, gastric cancer remains a frequent cause of cancer-related mortality. Indeed, this neoplasia is often diagnosed at an advanced stage, when the 5-year survival is $<5 \%$ [1]. Moreover, the prevalence is expected to remain high in the next decade due to the increasing population ageing [2]. Screening programs were found to distinctly improve patients' survival by anticipating a cancer diagnosis [3]. Nevertheless, screening is applicable only in areas with a high incidence of gastric cancer, such as Korea, Japan, and China [4]. In Caucasian populations, identification and follow-up of gastric precancerous lesions - atrophy and intestinal metaplasia (IM) - is the only practical procedure aimed at increasing the diagnosis of cancer at an early stage. Indeed, patients with extensive IM, i.e., diffused on both antrum and gastric body mucosa, have a distinctly high risk of developing neoplasia and deserve a scheduled follow-up according to the current guidelines [5]. This approach was recently suggested also for areas with a low incidence of gastric cancer, such as the USA, at least in population subgroups at an increased risk [6]. Is there an optimal age threshold for searching for extensive IM on gastric mucosa in West- ern countries with a low-intermediate gastric cancer incidence? We conducted the present study to answering this clinically relevant question.

\section{Materials and Methods}

This is a post hoc analysis of prospectively collected data. In detail, a nationwide study involving 24 endoscopy units enrolled consecutive Italian patients aged between 50 and 65 years between January 2012 and March 31, 2012 [7]. Patients were referred for upper endoscopy from general practitioners due to upper gastrointestinal symptoms. Those who had previously undergone gastroscopy were excluded. All patients underwent endoscopic examination with standard biopsy sampling to search for Helicobacter pylori infection and gastritis staging according to the updated Sydney System mapping. Briefly, 2 biopsies from the antrum, 1 from the angulus, and 2 from the gastric body were used for both histological and $H$. pylori infection assessments. For the purposes of this study, only the presence and distribution of IM on gastric mucosa were considered. From the original database, information on age, sex, BMI, smoking habits, a first-degree family history of gastric cancer, and the main symptom was acquired. Symptoms were categorized as dyspeptic, gastro-oesophageal reflux, or both.

Data were compared in a univariate analysis using the $\chi^{2}$ test, or the Fisher's exact test, as appropriate. A logistic regression analysis was performed by using extensive IM in the stomach as the dependent variable and age, sex, smoking, first-degree family history of gastric cancer, BMI, and type of symptoms as independent variables. Age was categorized into the following subgroups: 50$54,55-59$, and 60-65 years. Patients were considered to have a normal weight when their BMI was in the range of 18.5-24.9. Statistical analyses were performed using MedCalc ${ }^{\circledR}$ Statistical Software version 19.5.1 (MedCalc Software Ltd., Ostend, Belgium; https://www.medcalc.org; 2020).

\section{Results}

Data for 977 patients were available, including 456 (46.7\%) males, 247 (25.3\%) smokers, 431 (44.1\%) with a normal BMI, and 113 (11.6\%) with a first-degree family history of gastric cancer (Table 1). At the histological assessment, $H$. pylori infection was detected in $333(34.1 \%)$ patients, extensive IM metaplasia was found in 35 (3.6\%) patients, focal IM was found in 187 (19.1\%) patients, and extensive atrophy without IM was found in 51 (5.2\%) cases.

In the univariate analysis, the prevalence of extensive IM was $2 \%$ and $2.8 \%$ in patients aged $50-54$ and between 55 and 59 years, respectively, and it increased to $5.4 \%$ in those aged $60-65$ years, with a statistically significantly difference ( $p=0.014$ ) between patients aged 50-59 and those aged 60-65 years. In the latter patient group, al- 
Table 1. Distribution of characteristics by age group

\begin{tabular}{lccc}
\hline Characteristic & $\begin{array}{l}\text { Age 50-54 years } \\
(n=296)\end{array}$ & $\begin{array}{l}\text { Age 55-59 years } \\
(n=289)\end{array}$ & $\begin{array}{l}\text { Age 60-65 years } \\
(n=392)\end{array}$ \\
\hline Females & $188(63.5)$ & $180(62.3)$ & $253(64.5)$ \\
Smoking habit & $101(34.1)$ & $111(38.4)$ & $135(34.4)$ \\
Family history of gastric cancer & $37(12.5)$ & $27(9.3)$ & $49(12.5)$ \\
Dyspeptic symptoms & $121(40.9)$ & $128(44.3)$ & $168(42.9)$ \\
Reflux symptoms & $68(23)$ & $55(19)$ & $82(20.9)$ \\
Dyspeptic and reflux symptoms & $57(19.2)$ & $57(19.7)$ & $74(18.9)$ \\
Others & $26(8.7)$ & $24(8.3)$ & $38(4.6)$ \\
BMI & $10(3.4)$ & $8(2.8)$ & $6(1.5)$ \\
$\quad<18.5$ & $154(52.0)$ & $114(39.4)$ & $163(41.6)$ \\
$\quad \geq 18.5-24.9$ & $81(27.4)$ & $121(41.9)$ & $169(43.1)$ \\
$\quad \geq 25-29.9$ & $51(17.2)$ & $45(15.6)$ & $54(13.8)$ \\
$>30$ & & & \\
\hline
\end{tabular}

though the values of extensive IM prevalence were higher in males and in patients with dyspeptic symptoms, as was the presence of a family history of gastric cancer, a smoking habit, or abnormal weight, the differences were not statistically significant (Table 2a). Similarly, no differences emerged in other age groups (Table $2 b, c)$. In the multivariate analysis, only age $>60$ years was a factor independently associated with an increased prevalence of extensive IM (Table 3), with an adjusted OR of 2.28 (95\% CI 1.14-4.55).

\section{Discussion/Conclusion}

Gastric cancer remains a neoplasia with a dismal prognosis when diagnosed at an advanced stage [1]. Unfortunately, screening programs successfully implemented in Asian populations are not practicable in areas with a lowintermediate incidence. Therefore, identification and scheduled follow-up of precancerous lesions on gastric mucosa is a plausible approach aimed at discovering noninvasive neoplasia or early gastric cancer, and the identification of high-risk groups would reduce the endoscopic surveillance burden and related costs [5]. Therefore, we investigated whether age and some clinical characteristics predict the presence of extensive IM in the stomach. Our data found that the prevalence of extensive IM was distinctly increased in patients aged 60-65 years, with a 2.28fold increased risk compared to younger (age 50-59 years) subjects. None of the other considered factors emerged as an independent predictor in the multivariate analysis.

From the point of view of potential screening, we focused our investigation on extensive IM and in subjects aged 50-65 years based on some considerations. Among gastric precancerous lesions, the diagnosis of IM ( $k=$ $0.87)$ is distinctly more accurate than that of atrophy $(k=$ 0.64 ) [8], and extensive IM harbors a gastric cancer risk that is twice that of extensive atrophy $[9,10]$. Moreover, IM - but not atrophy - is accurately detected and staged at virtual chromoendoscopy, with an undoubted advantage for patient selection [11]. Therefore, extensive IM might represent an appropriate target for secondary prevention of gastric cancer [10]. On the other hand, subjects with an age ranging from 50 to 65 years could represent a potential target population for screening. Age $\geq 50$ years is the lower threshold recommended by Italian guidelines for performance of an upper endoscopy in dyspeptic patients [12]. Moreover, we limited the evaluation to 65 -year-old subjects because the gastric cancer incidence in Italy is $4-5$ times higher in subjects aged $>70$ years [13]. These data were confirmed in a recent study showing that age $>70$ years was associated with a 9 -fold higher probability of development of gastric epithelial neoplastic lesions in patients with gastric precancerous lesions [14]. It has been suggested that screening programs for gastric cancer in intermediate-risk European countries could be cost-effective if combined with a scheduled screening colonoscopy starting at 50 years of age [15]. Based on the data of present study, upper endoscopy could be proposed to 60- to 65-years-old subjects, allowing the identification of high-risk patients who require a scheduled follow-up.

In conclusion, upper endoscopy performed at age 60 years in dyspeptic patients allows optimization of the possibility of detecting extensive IM and identifying the small (5.4\%) patients subgroup in need of a scheduled follow- 
Table 2. Prevalence of extensive IM

a In patients aged $\geq 60$ years according to other factors $(n=392)$

\begin{tabular}{lcc}
\hline & Extensive IM & $p$ value \\
\hline Sex (male/female) & $9(6.5) / 12(4.7)$ & 0.4 \\
Smoking habit (yes/no) & $9(6.5) / 12(4.7)$ & 0.4 \\
Family history (yes/no) & $3(6.1) / 18(5.2)$ & 0.8 \\
H. pylori (yes/no) & $6(4.6) / 15(5.7)$ & 0.6 \\
Normal BMI (yes/no) & $7(4.1) / 14(6.5)$ & 0.3 \\
Dyspeptic symptoms (yes/no) & $12(7.1) / 9(4.0)$ & 0.2 \\
Reflux symptoms (yes/no) & $4(4.9) / 17(5.5)$ & 0.3 \\
Dyspeptic and reflux symptoms (yes/no) & $3(3.0) / 18(6.2)$ & 0.2 \\
\hline
\end{tabular}

b In patients aged 55-59 years according to other factors $(n=289)$

\begin{tabular}{lll}
\hline & Extensive IM & $p$ value \\
\hline Sex (male/female) & $2(1.8) / 6(3.3)$ & 0.7 \\
Smoking habit (yes/no) & $2(1.8) / 6(3.4)$ & 0.7 \\
Family history (yes/no) & $1(3.7) / 7(2.7)$ & 0.5 \\
H. pylori (yes/no) & $5(4.8) / 3(1.6)$ & 0.1 \\
Normal BMI (yes/no) & $4(3.5) / 4(2.3)$ & 0.7 \\
Dyspeptic symptoms (yes/no) & $2(1.6) / 6(3.7)$ & 0.3 \\
Reflux symptoms (yes/no) & $2(3.6) / 6(2.6)$ & 0.6 \\
Dyspeptic and reflux symptoms (yes/no) & $1(1.2) / 7(3.4)$ & 0.4 \\
\hline
\end{tabular}

c In patients aged 50-54 years according to other factors $(n=296)$

\begin{tabular}{lll}
\hline & Extensive IM & $p$ value \\
\hline Sex (male/female) & $2(1.8) / 4(2.1)$ & 1.0 \\
Smoking habit (yes/no) & $4(4.0) / 2(1.0)$ & 0.2 \\
Family history (yes/no) & $1(2.7) / 5(1.9)$ & 0.5 \\
H. pylori (yes/no) & $3(3.1) / 3(1.5)$ & 0.4 \\
Normal BMI (yes/no) & $4(3.5) / 4(2.3)$ & 0.7 \\
Dyspeptic symptoms (yes/no) & $3(2.5) / 3(1.7)$ & 0.7 \\
Reflux symptoms (yes/no) & $2(2.9) / 4(1.8)$ & 0.6 \\
Dyspeptic and reflux symptoms (yes/no) & $0(0) / 6(2.8)$ & 0.2
\end{tabular}

Values are presented as numbers (\%).

Table 3. Predictors of extensive intestinal metaplasia in the multivariate analysis

\begin{tabular}{|c|c|c|c|c|c|}
\hline Factor & Raw data & OR & Adjusted OR & $95 \%$ CI & $p$ value \\
\hline Age $\geq 60$ years & $21 / 35-371 / 942$ & 2.30 & 2.28 & $1.14-4.55$ & 0.019 \\
\hline Dyspeptic symptoms & $17 / 35-400 / 942$ & 1.28 & 1.52 & $0.68-3.38$ & 0.30 \\
\hline Reflux symptoms & 8/35-197/942 & 1.12 & 1.44 & $0.55-3.75$ & 0.45 \\
\hline BMI & $22 / 35-499 / 942$ & 1.50 & 1.41 & $0.69-2.87$ & 0.33 \\
\hline Smoking habit & $15 / 35-335 / 942$ & 1.35 & 1.37 & $0.67-2.79$ & 0.38 \\
\hline Ongoing $H$. pylori infection & $14 / 35-319 / 942$ & 1.30 & 1.29 & $0.65-2.59$ & 0.46 \\
\hline Family history of gastric cancer & $5 / 35-108 / 942$ & 1.29 & 1.24 & $0.47-3.28$ & 0.67 \\
\hline Gender & $22 / 35-599 / 942$ & 0.97 & 1.07 & $0.52-2-22$ & 0.84 \\
\hline
\end{tabular}


up. Therefore, when deciding on occasional gastric cancer screening in Western populations, the choice of a cutoff age $>60$ years might be appropriate.

\section{Statement of Ethics}

This is post hoc study on anonymously collected data. Therefore, ethical approval was deemed not mandatory.

\section{Conflict of Interest Statement}

The authors have no conflict of interests to declare.

\section{Funding Sources}

No fund was received for this paper.

\section{Author Contributions}

A.Z. and B.A. conceived this study and wrote this paper. G.E. performed the data analysis. E.L. and C.H. participated with constructive criticism. All of the authors approved the final version of this work.

\section{References}

1 Smith DD, Schwarz RR, Schwarz RE. Impact of total lymph node count on staging and survival after gastrectomy for gastric cancer: data from a large US-population database. J Clin Oncol. 2005 Oct;23(28):7114-24.

2 Arnold M, Park JY, Camargo MC, Lunet N, Forman D, Soerjomataram I. Is gastric cancer becoming a rare disease? A global assessment of predicted incidence trends to 2035. Gut. 2020 May;69(5):823-9.

3 Zhang X, Li M, Chen S, Hu J, Guo Q, Liu R, et al. Endoscopic screening in Asian countries is associated with reduced gastric cancer mortality: a meta-analysis and systematic review. Gastroenterology. 2018 Aug;155(2):347-54. e9.

4 Ajani JA, Lee J, Sano T, Janjigian YY, Fan D, Song S. Gastric adenocarcinoma. Nat Rev Dis Primers. 2017 Jun;3(1):17036.

5 Pimentel-Nunes P, Libânio D, Marcos-Pinto R, Areia M, Leja M, Esposito G, et al. Management of epithelial precancerous conditions and lesions in the stomach (MAPS II): European Society of Gastrointestinal Endoscopy (ESGE), European Helicobacter and Microbiota Study Group (EHMSG), European Society of Pathology (ESP), and Sociedade Portuguesa de Endoscopia Digestiva (SPED) guideline update 2019. Endoscopy. 2019 Apr; 51(4):365-88

6 Huang RJ, Koh H, Hwang JH, Abnet CC, Alarid-Escudero F, Amieva MR, et al.; Summit Leaders. A summary of the 2020 gastric cancer summit at Stanford University. Gastroenterology. 2020 Oct;159(4):1221-6.

7 Lahner E, Zullo A, Hassan C, Perri F, DinisRibeiro M, Esposito G, et al.; MAG-Study Group. Detection of gastric precancerous conditions in daily clinical practice: a nationwide survey. Helicobacter. 2014 Dec;19(6): 417-24.

8 Capelle LG, de Vries AC, Haringsma J, Ter Borg F, de Vries RA, Bruno MJ, et al. The staging of gastritis with the OLGA system by using intestinal metaplasia as an accurate alternative for atrophic gastritis. Gastrointest Endosc. 2010 Jun;71(7):1150-8.

9 Song H, Ekheden IG, Zheng Z, Ericsson J, Nyrén O, Ye W. Incidence of gastric cancer among patients with gastric precancerous lesions: observational cohort study in a low risk Western population. BMJ. 2015 Jul; 351:h3867.

10 Yue H, Shan L, Bin L. The significance of OLGA and OLGIM staging systems in the risk assessment of gastric cancer: a systematic re- view and meta-analysis. Gastric Cancer. 2018 Jul;21(4):579-87.

11 Esposito G, Pimentel-Nunes P, Angeletti S, Castro R, Libânio D, Galli G, et al. Endoscopic grading of gastric intestinal metaplasia (EGGIM): a multicenter validation study. Endoscopy. 2019 Jun;51(6):515-21.

12 Zagari RM, Romano M, Ojetti V, Stockbrugger R, Gullini S, Annibale B, et al. Guidelines for the management of Helicobacter pylori infection in Italy: The III Working Group Consensus Report 2015. Dig Liver Dis. 2015 Nov; 47(11):903-12.

13 Associazione Italiana Registri Tumori. Stomach cancer: cancer in Italy. 2009. Available from: www.registri-tumori.it.

14 Esposito G, Dilaghi E, Cazzato M, Pilozzi E, Conti L, Carabotti M, et al. Endoscopic surveillance at 3 years after diagnosis, according to European guidelines, seems safe in patients with atrophic gastritis in a low-risk region. Dig Liver Dis. 2020, Online ahead of print.

15 Areia M, Spaander MC, Kuipers EJ, Dinis-Ribeiro M. Endoscopic screening for gastric cancer: A cost-utility analysis for countries with an intermediate gastric cancer risk. United European Gastroenterol J. 2018 Mar;6(2): 192-202. 